\title{
QUEEN'S
UNIVERSITY
BELFAST
}

\section{Bringing the battlefield into the classroom: using video games to teach and assess international humanitarian law}

Moffett, L., Cubie, D., \& Godden, A. (2017). Bringing the battlefield into the classroom: using video games to teach and assess international humanitarian law. The Law Teacher, 51.

https://doi.org/10.1080/03069400.2017.1356659

Published in:

The Law Teacher

Document Version:

Peer reviewed version

Queen's University Belfast - Research Portal:

Link to publication record in Queen's University Belfast Research Portal

Publisher rights

() 2017 The Association of Law Teachers.

This work is made available online in accordance with the publisher's policies. Please refer to any applicable terms of use of the publisher.

\section{General rights}

Copyright for the publications made accessible via the Queen's University Belfast Research Portal is retained by the author(s) and / or other copyright owners and it is a condition of accessing these publications that users recognise and abide by the legal requirements associated with these rights.

Take down policy

The Research Portal is Queen's institutional repository that provides access to Queen's research output. Every effort has been made to ensure that content in the Research Portal does not infringe any person's rights, or applicable UK laws. If you discover content in the Research Portal that you believe breaches copyright or violates any law, please contact openaccess@qub.ac.uk. 


\section{Bringing the Battlefield into the Classroom: Using Video Games to Teach and}

\section{Assess International Humanitarian Law}

\section{Introduction}

War has never been as close and safe for the casual observer, whether through 24-hour news, video footage of aerial bombings, frontline journalism or social media. As evidenced by the rapid increase in the use of drones and semi-autonomous weaponry, technology is 'transforming how wars are fought' and how 'we imagine war'. ${ }^{1}$ Simultaneously, entertainment is imitating life in such a technological-driven age with the multi-billion dollar video gaming industry immersing gamers into increasingly realistic combat scenarios. Divorced from the consequences of war, such first-person shooter games ${ }^{2}$ enable players to fire and forget - for example by shooting civilians, calling in drone strikes to take out hospitals or carrying out a multitude of other actions, such as torture, which would be classified as war crimes if they occurred in real life. This detached reality belies the horror of war that is all too often inflicted on civilians and soldiers who are hors de combat. ${ }^{3}$ Few of these games adequately reflect humanitarian principles or the detailed provisions of the international law of armed conflict (often termed 'International Humanitarian Law') $)^{4}$ that guide and frame the use of force in actual combat. As Anderson and Kurti pointedly note 'the thrilling excitement of entertainment replaces the emotional truth of war'.5

\footnotetext{
${ }^{1}$ B. Clarke, C. Rouffaer and F. Sénéchaud, 'Beyond the Call of Duty: Why Shouldn't Video Game Players Face the Same Dilemmas as Real Soldiers?' (2012) 94(886) International Review of the Red Cross 711-738, 714.

${ }^{2} \mathrm{~A}$ first-person shooter is a popular type of video game that involves the gamer playing from the personal point of view of a soldier - seeing the weapon in their hands and shooting at targets as they appear on the screen.

${ }^{3}$ As per the 1949 Geneva Conventions, those 'hors de combat' are former combatants who are not taking any active part in the conflict, such as prisoners of war or the wounded and sick.

${ }^{4}$ In this article we use the terms 'law of armed conflict' and 'international humanitarian law (IHL)' synonymously. See Y. Dinstein, The Conduct of Hostilities under the Law of International Armed Conflict ( $2^{\text {nd }}$ edn., Cambridge University Press 2010), p18-19.

${ }^{5}$ R. Andersen and M. Kurti, 'From America's Army to Call of Duty: Doing Battle with the Military Entertainment Complex' (2009) 23(1) Democratic Communiqué 45-65, p45.
} 
Conversely, advanced military technology is removing the human actor from real-world battlefields, for example through the use of remote controlled armed drones. ${ }^{6}$ Moreover, running parallel to the growing realism of video games is the gamification of combat, whereby military training and simulations increasingly resemble popular games, such as Call of Duty or Battlefield, ${ }^{7}$ which risks desensitising soldiers to the use of force. ${ }^{8}$ As a result, there is a profound need to reinforce not just the complex body of legal rules that regulate the use of force in the real world, but also the fundamental role that the principles of humanity and human dignity play in all military actions. ${ }^{9}$ Moreover, while there is increasing appreciation of the role of technology in warfare and its legitimatisation through computer games, ${ }^{10}$ as well as growing literature on computer games as a teaching and assessment tool, there has been little overlap in using war simulations to teach the laws of war.

Against this backdrop, the School of Law at Queen's University Belfast (QUB) has been engaged in a series of innovative teaching approaches with undergraduate and postgraduate students to reflect the contemporary application of international humanitarian law (IHL). Commencing in early 2014, the authors developed two new modules for the Law curriculum. The first was a pilot six-week postgraduate (LLM) module on International Humanitarian Law, which formed the basis of a more detailed 12-week optional module for third year undergraduates and separately for LLM students. Over the course of developing this 12-week

\footnotetext{
${ }^{6}$ Non-state armed groups can also access and modify technology such as low-cost attack drones. See: 'Photos Show "Weaponised Commercial Drones" in Iraq', BBC News Online, 18 January 2017, available at: www.bbc.com/news/technology-38663394

7 The Call of Duty franchise is a series of first-person shooter games developed by Activision Blizzard. Indicative of the size of the video game market, the various Call of Duty games have sold over 250 million copies and grossed over US\$15 billion since they were launched in 2003. See: 'Activision Blizzard Announces Fourth Quarter and Full Year $2015 \quad$ Financial Results' (11 February 2016) available at: www.businesswire.com/news/home/20160211006451/en. The Battlefield series of games have been running since 2002 and are developed EA DICE.

${ }^{8}$ See: K. Taylor, The Brain Supremacy: Notes from the Frontiers of Neuroscience, (Oxford University Press 2012).

${ }^{9}$ See: T. Meron, 'The Humanization of Humanitarian Law' (2000) 94 American Journal of International Law 239278; J. Cerone, 'Human Dignity in the Line of Fire: The Application of International Human Rights Law During Armed Conflict, Occupation, and Peace Operations' (2006) 39 Vanderbilt Journal of Transnational Law 14471510. See also: See Clarke, Rouffaer and Sénéchaud, 'Beyond the Call of Duty' (n.1).

${ }^{10}$ See Clarke, Rouffaer and Sénéchaud, 'Beyond the Call of Duty' (n.1); and C. Newbery-Jones, 'Answering the Call of Duty: The Phenomenology of Justice in Twenty-First Century Video Games' (2015) 9(1) Law and Humanities 78.
} 
IHL module, the authors secured funding from the QUB e-AFFECT learning project ${ }^{11}$ to develop an interactive student learning and assessment tool through modification of the Arma 3 first-person shooter video game. Drawing on Howard Gardner's theory of multiple intelligences, a series of computer simulations were therefore developed to provide an immersive experiential entry point to learning for the students.

This article explores the role of using computer games to teach ethical thinking and problem solving within international humanitarian law. The article begins by discussing the unique nature of international humanitarian law and how it lends itself to more intuitive real world problem solving based on competing principles. The following section explains the planning and development process of using Arma3 to teach international humanitarian law and assess students' understanding and problem solving skills. The subsequent section identifies the preliminary and on-going pedagogical impact and learning points arising from the use of this interactive student learning and assessment tool. The final section reflects on the challenges and lessons learnt from the Arma3 project, that while students were keen to engage with technology in class, there were unforeseen technical challenges that required rethinking its use as a form of summative assessment. However, to fully understand the rationale for and potential benefits from such a project, it is useful to first examine some of the specific issues which arise from teaching international humanitarian law in general.

\section{Teaching International Humanitarian Law}

Within an academic setting, the teaching of international humanitarian law (IHL) occupies a unique position, as it essentially revolves around explaining to students how people can be legally maimed or killed. This runs counter to core legal principles, such as those within domestic criminal and tort law, which clearly identify the sanctions against actions which harm,

\footnotetext{
${ }^{11}$ The e-Assessment and Feedback for Effective Course Transformation (e-AFFECT) project within QUB was a JISC funded project which aimed to transform staff and student experience of assessment and feedback across QUB through the effective use of technology. For more information, see: www.qub.ac.uk/directorates/AcademicStudentAffairs/CentreforEducationalDevelopment/e-AFFECTproject/
} 
injure or kill people. For students (and indeed for many academics and practitioners) this dissonance is the first of many threshold concepts which must be addressed. ${ }^{12}$ A second central, yet potentially difficult to grasp, concept within the teaching of IHL is the reliance on a broad range of sources of the 'law'. For undergraduate common law students versed in the black letter law of statutes and case law, the move into public international law with its emphasis on both 'hard' international conventions and 'soft' guiding principles, minimum standards and UN resolutions (where many of the fundamental humanitarian principles which influence actions in combat zones originate) presents an additional hurdle to surmount. One of the key objectives of the QUB e-AFFECT IHL project was therefore to train students in identifying and understanding not only key threshold concepts found within IHL, but also to develop key threshold skills, in other words the practical application of knowledge through decision-making in realistic combat scenarios. ${ }^{13}$

While the law of armed conflict is one of the oldest branches of international law, ${ }^{14}$ originating with the 1864 Geneva Convention and the establishment of the International Committee of the Red Cross, it was the horrific experiences of the Second World War that precipitated the ever-expanding corpus of modern IHL. ${ }^{15}$ Foundational are the four 1949 Geneva Conventions and three Additional Protocols, alongside a raft of global conventions prohibiting the use of certain types of weapons, such as anti-personnel mines ${ }^{16}$ and cluster munitions. ${ }^{17}$ However, international law trails both technological advancements and evolving combat scenarios. While guerrilla warfare has been a feature of conflicts for decades, since the

\footnotetext{
${ }^{12}$ G. Cousin, 'An Introduction to Threshold Concepts' (December 2006) 17 Planet 4-5.

${ }^{13}$ See L. Thomas et el, 'A Broader Threshold: Including Skills as well as Concepts in Computing Education' in C. O'Mahony, A. Buchanan, M. O'Rourke and B. Higgs (eds.), Threshold Concepts: From Personal Practice to Communities of Practice (Proceedings of the National Academy's Sixth Annual Conference and Fourth Biennial Threshold Concepts Conference) (Ireland: NAIRTL, 2014) 154-158.

${ }^{14}$ See James Gallen and Colin Smith, Cáin Adomnáin and the Laws of War, Journal of the History of International Law 16(1) (2014) 63-81, on its roots in Brehon Law.

${ }^{15}$ See: D. Palmieri, 'An Institution Standing the Test of Time? A Review of 150 Years of the History of the International Committee of the Red Cross' (Spring 2013) 95(889) International Review of the Red Cross 1-26.

${ }^{16}$ Convention on the Prohibition of the Use, Stockpiling, Production and Transfer of Anti-Personnel Mines and on Their Destruction, 2056 UNTS 211 (adopted 18 September 1997; entered into force 1 March 1999).

${ }^{17}$ Convention on Cluster Munitions (adopted 30 May 2008; entered into force 1 August 2010).
} 
end of the Cold War there has been an increasing trend away from 'traditional' inter-state wars fought between professional armies, to so-called 'asymmetrical' conflict between militarily advanced countries and non-state armed groups. ${ }^{18}$ Concomitantly, the geographic reach of the battlefield has expanded through the increasing use of technology (for example through armed drones, cyber-warfare and the weaponisation of space). We have also witnessed the horrific and complete disregard for humanitarian principles and the provisions of IHL by a variety of armed groups, not least in the long-running Syrian conflict (such as attacks on hospitals and the use of chemical weapons), the barbaric actions of Daesh/Islamic State (including beheadings of civilians and the destruction of cultural property), and the widespread use of rape and sexual violence as a weapon of war by groups such as the Lord's Resistance Army in the Great Lakes region. $^{19}$

At its core, IHL is guided by the balancing of four fundamental principles: distinction between civilians and combatants; proportionality in attack; precaution in attack; and military necessity. These principles stress that the use of force within war is not unlimited, and attempt to ensure that combat is conducted in the most humane way possible without frustrating the military necessity to achieve an advantage over the enemy. The principle of distinction requires belligerents to distinguish between civilians and combatants, as well as civilian and military objects. $^{20}$ This requires belligerents not to target civilians or use indiscriminate weapons (such as chemical weapons). ${ }^{21}$ Proportionality is two-fold. First, it obliges belligerents only to use as much force as necessary in attack so as not to cause excessive loss or injury to civilians in relation to the military advantage gained. ${ }^{22}$ Second, belligerents are prohibited from using weapons that will cause 'superfluous injury or unnecessary suffering', such as anti-personnel

\footnotetext{
18 M. Sassòli, 'Taking Armed Groups Seriously: Ways to Improve their Compliance with International Humanitarian Law' (2010) 1 Journal of International Humanitarian Legal Studies 5-51.

${ }^{19}$ L. Moffett, 'Accountability for Forced Displacement in Democratic Republic of Congo and Uganda before the International Criminal Court’ (2015) 1(2) African Journal of International Criminal Justice 129-152.

${ }^{20}$ Article 48, 1977 Additional Protocol I.

${ }^{21}$ Dinstein n.4 p62-88.

${ }^{22}$ Article 51(5)(b), Additional Protocol I.
} 
mines or biological weapons. ${ }^{23}$ The International Court of Justice has stressed that distinction and proportionality are the 'cardinal principles ... constituting the fabric' of IHL. ${ }^{24}$ The principle of precaution requires commanders to take constant care in carrying out attacks to spare civilians by placing military objects and objectives away from civilian populations and objects, to avoid and minimise loss of life to civilians in their use of weapons, and to give an effective warning if circumstances permit. ${ }^{25}$ Military necessity is the counter-balance to the three other principles and recognises that international law authorises the use of armed and lethal force in certain circumstances. However, when an army or armed group engages in the use of force, they are required to consider both prevailing military and humanitarian considerations; in other words, to balance the expected military advantage to be gained with the direct or collateral damage which may occur.

For students, learning about the law of armed conflict from books provides only one source of knowledge and understanding. Witnessing conflict and its consequences are key to appreciating the impact of decisions and obligations during combat. Yet there are clear moral and ethical issues around utilising real war-related footage that graphically shows the full complexity and horror of war. On the other hand, sanitising violence risks that students will not appreciate the devastating consequences of military action on combatants and civilians, which may result in them recommending more violent or unlawful behaviour in their problem solving and application of the law. ${ }^{26}$

It is here that video games have potential as a powerful learning tool to allow the law teacher to have full control of relevant topical issues, while minimising the voyeurism attendant to traumatic human consequences. By its nature, war is a complex and ever-changing series of events, and combatants often must make instantaneous life-or-death decisions based on scant or

\footnotetext{
${ }^{23}$ Article 35(2), Additional Protocol I.

${ }^{24}$ ICJ, Legality of the Threat or Use of Nuclear Weapons, Advisory Opinion, 1996, ICJ Reports (8 July 1996) para.78.

${ }^{25}$ Article 57, Additional Protocol I.

${ }^{26}$ Andersen and Kurti n.5, p51.
} 
unreliable intelligence. For example, if a speeding car is approaching a military checkpoint, does it contain a heavily pregnant civilian woman in need of urgent medical care, or is this a suicide bomber intent on causing maximum damage to the checkpoint? This learning paradox - the need for students to understand the fundamental principles and relevant law contrasted with their ability to apply this knowledge in a realistic, yet safe, environment - motivated the QUB eAFFECT IHL project. This therefore necessitated the lecturing staff to identify creative teaching and learning opportunities to bring the battlefield into the classroom.

Both military and humanitarian practitioners utilise teaching and training simulations, including through realistic role-play scenarios. For example, the biannual VIKING civil-military training exercises conducted under the auspices of NATO's Partnership for Peace initiative comprise week-long, real-time training exercises. The latest exercise in 2014 brought together 2,500 participants from military and humanitarian organisations from over 50 countries, including students. ${ }^{27}$ Likewise, national and international IHL competitions have become popular over the past few years involving universities, the Red Cross and militaries, such as the ICRC's Jean Pictet moot court competition ${ }^{28}$ and the Irish Red Cross Society's Corn Adomnáin competition. ${ }^{29}$ While such role-playing scenarios are challenging and require strong teamwork, ${ }^{30}$ they do not lend themselves well to individual assessment, particularly with classes of forty or more students. Therefore, drawing on the authors' professional experience in academia and working for humanitarian organisations, the use of video games as a learning and assessment tool was identified as a means of not only providing a number of entry points to learning to stimulate student interest but also to encourage students to actively apply their knowledge and understanding of IHL to evolving real world scenarios.

\footnotetext{
27 See for example: 'Viking 14 Evaluation Conference', Folke Bernadotte Academy, https://fba.se/en/newspress/nyhetsarkiv/2014/VIKING-14-Evaluation-Conference/ (20 May 2014); 'LLM Students Participate in Civil-Military Training Exercise Viking14', School of Law, University College Cork (15 April 2014), www.ucc.ie/en/law-postgrad/news/

${ }^{28}$ See: www.icrc.org/en/document/he-2015-jean-pictet-moot-court-competition

${ }^{29}$ See: www.redcross.ie/programmes-and-services-in-ireland/corn-adomnain/

${ }^{30}$ F. Hampson, 'Teaching the Law of Armed Conflict' (July 2008) 5(1) Essex Human Rights Review.
} 


\section{Using Arma 3 for Teaching and Assessment}

Militaries have long recognised the skills development that video games can bring through their repetitive drill structure and requirement to follow commands that are incentivised through rewards and progression. ${ }^{31}$ Governments are therefore increasingly turning to military simulations such as America's Army to safely transfer knowledge and skills to their cadets, as well as their use as a recruitment tool. ${ }^{32}$ For gamers, such militaristic video games move beyond the passive consumption of other forms of entertainment involving war, such as television or film, by making them 'active participants in simulated warfare'. ${ }^{33}$ This is what Stahl calls 'militainment', where war is 'packaged for pleasurable consumption' and 'entertainment with military themes in which the (US) Department of Defense is celebrated'. ${ }^{34}$

Not all video games lend themselves to being used as teaching material. Some video games follow a linear story line that does not engage with IHL or allow scenarios to be manipulated for course content. A further problem is that many first-person shooters portray the battlefield as either an 'open shooting range where no precautions are to be taken' or where there are no civilians or persons hors de combat. ${ }^{35}$ More disturbingly, these games can involve scenarios such as torturing a prisoner for information, or going undercover in a terrorist cell and attacking an airport where the gamer is actively encouraged to target unarmed civilians. ${ }^{36}$ In such scenarios the player is neither reprimanded by commanding officers within the game nor suffers a penalty score and so such actions are normalised. As a result, it has been argued that

\footnotetext{
${ }^{31}$ Clarke, Rouffaer and Sénéchaud n.1, p717.

${ }^{32}$ Andersen and Kurti, n.5. America's Army is a video game first person shooter series developed by the US Army as a recruitment, training and educational tool by providing a realistic experience of soldiers' experience in combat.

${ }^{33}$ Clarke, Rouffaer and Sénéchaud, n.1, p714.

${ }^{34}$ R. Stahl, Militainment, Inc. - War, Media and Popular Culture (Routledge 2009) p6.

${ }^{35}$ Clarke, Rouffaer and Sénéchaud, 'Beyond the Call of Duty' (n.1) 721.

${ }^{36}$ As occurs in the so-called 'No Russian' mission in Call of Duty: Modern Warfare 2 (2009). For discussion of this point, see: G. Brown, D. Greenberg, S. Hudson and K. Sanger, 'Rules of the (Video) Game: IHL on the Virtual Battlefield' (2015) 109 Proceedings of the Annual Meeting of the American Society of International Law 55-61, 58. See also: N. Hohl, 'Why No Russian Is The Most Controversial Video Game Level Ever' (16 March 2016) http://opshead.com/article/619/why-no-russian-is-the-most-controversial-video-game-level-ever
} 
such games can be used as propaganda to 'glorify war' ${ }^{37}$ or legitimise conflict. ${ }^{38}$ While such actions can be dismissed as simply virtual entertainment, drawing from research conducted into why combatants commit atrocities Clarke et al suggested that such justification of torture or inhumane behaviour which distances the perpetrator from their victim is often replicated in warfare. ${ }^{39}$

Video games, in particular first-person shooters, have long been criticised from some quarters as encouraging violent behaviour in real life through normalising killing and the use of violence. ${ }^{40}$ Moreover, game play in first-person shooters is often a shooting range where apart from your allied non-player characters or friends, everyone else is an enemy that can be targeted and killed. These anonymous, and often stereotyped, enemies can therefore become 'abstractions in human form' resulting in the gamer's desensitisation to the 'brutalities of war'. ${ }^{41}$ Yet in the real world civilians are often unable to flee war zones or are caught between warring factions, and combatants may embed themselves within civilian populations to gain protection from enemy bombardment. The absence of civilians from these games simplifies the realities of warfare and its often devastating impact of civilians and those hors de combat. ${ }^{42}$ As Brown et al point out the individual gamer and the first-person shooting games market is not looking to peddle lessons in morality, but entertainment. ${ }^{43}$

Nevertheless, the decision to use computer simulations was premised on Howard Gardner's multiple entry points to learning perspective. For example, explaining the background to the fictional civil war set out in the simulations over the course of the module provided a narrative entry point, as well as introducing the students to the visual look of the virtual world.

\footnotetext{
${ }^{37}$ Schulzke n.42, p578.

${ }^{38}$ P. Mantello, 'Legitimacy and the Virtual Battlefield: Putting the First-person Shooter on the Witness Stand' (2013) 67(5) Australian Journal of International Affairs 638-658.

${ }^{39}$ Clarke, Rouffaer and Sénéchaud n.1, p722, citing D. Muñoz-Rojas and J. Frésard, 'The Roots of Behaviour in War - Understanding and Preventing IHL Violations' (March 2004) 86(853) International Review of the Red Cross 169-188. See also: Andersen and Kurti, 'From America's Army to Call of Duty' (n.5) 59.

40 Andersen and Kurti n.5, p57.

${ }^{41}$ Ibid. p59.

${ }^{42}$ M. Schulzke, 'War by Other Means: Mobile Gaming and the 2014 Israel-Gaza Conflict' (2016) 42 Review of International Studies 575-596, 595.

${ }^{43}$ Brown et al, n.36, p59.
} 
Combined with this, students were expected to engage in a more traditional approach to studying the laws of armed conflict, via reading the primary legal texts and commentaries on these - thereby providing a logical-quantitative entry point to the subject. Finally, students were immersed into the virtual world as part of their final assessment, with the intention of providing a memorable and challenging experiential entry point to learning and understanding the difficulties of making real-time decisions based on the law in an armed conflict. ${ }^{44}$

Moreover, virtual simulations can enable students to develop new real-time skills, through active participation and responsibility to resolve challenging scenarios that would otherwise not be possible or safe within a classroom. ${ }^{45}$ In video games, players can be incentivised through completing an objective, overpowering the enemy or just surviving, through rewards such as advancing to the next level, improving their 'rank' and unlocking new items, such as weapons, medals or avatars. ${ }^{46}$ In the same way, players can be incentivised through the use of score or time penalties, the failure of a mission or simply on-screen warnings for those who target civilians or protected objectives (as occurs if a gamer targets a church in the aerial bombardment mission in Call of Duty 4). The ultimate incentive not to commit actions contrary to the law of armed conflict can be seen in the game Arma 3, the game utilised in the QUB e-AFFECT IHL project. In Arma 3, if a gamer deliberately attacks civilians or other protected persons their own squad mates immediately kill them. This can help to confront gamers with some form of detrimental consequence for their actions, reflecting the gravity such actions would be viewed in the real world as war crimes. ${ }^{47}$

Video game developers and gamers themselves go to extraordinary lengths to achieve visual and audio realism in these large-scale games. For example, developers try to ensure that each weapon sounds as its real-life counterpart does, and that the characters respond to the recoil

\footnotetext{
${ }^{44}$ H. Gardner, The Unschooled Mind: How Children Think and How Schools Should Teach (2 ${ }^{\text {nd }}$ ed, Basic Books 1991), p.245.

${ }^{45}$ Newbery-Jones, n.10, p101.

${ }^{46}$ Brown et al n.36, p58.

${ }^{47}$ Ibid.
} 
or impact of weapons fired in a realistic manner. Yet realistic constraints on action arising from IHL are rarely included. Therefore, to inform this multi-billion-dollar market, the International Committee of the Red Cross has partnered with video game manufacturers to incorporate the rules of war into video games and to use such virtual tools as its next generation of education tools in promoting IHL. In particular, the ICRC has worked closely with the developers of Arma 3, including a prize for the best modification of the game to teach gamers, practitioners and students about the protection of medical personnel during hostilities. ${ }^{48}$

The video game Arma 3 is a publically-available military simulator using real world physics and military weapons and vehicles. As the game's publicity proclaims: 'This Is War. Experience true combat gameplay in a massive military sandbox. Authentic, diverse, open Arma 3 sends you to war.' 49 The game enables the gamer (or 'instructor') to create their own missions, using maps and materials in the game. The game revolves around two fictional islands (Altis and Stratis) which are described as 'quaint, Mediterranean islands ravaged by hostile occupation. ${ }^{50}$ Reflecting the open nature of the game, instructors can either conduct a campaign based on pre-programmed mission scenarios, interact in a free-flowing multi-player game online, or develop bespoke missions within the Altis and Stratis environment. It was this final attribute of Arma 3 which facilitated its use as an educational learning and assessment tool. Therefore, the following section will review the planning process that took place within the QUB School of Law during 2014-15, leading to the development of five scenarios for use with the students.

\section{Development and Testing Process}

\section{i. Pilot project and initial feedback}

\footnotetext{
${ }^{48} \mathrm{See}$ http://blogs.icrc.org/new-delhi/2014/08/01/make-arma-not-war-saving-lives-through-virtual-battlefields/

${ }^{49}$ For more information on Arma 3, see: https://arma3.com/

${ }^{50}$ See: https://arma3.com/features/terrain
} 
The initial basis for the use of computer simulations in the teaching of IHL came from a series of publically available non-interactive scenarios developed by the ICRC within the Arma 3 framework. These four scenarios covered the fundamental principles of distinction, proportionality, precaution and the prohibition of perfidy (improper use of the protected emblems of the Red Cross). Within the original 6-week LLM module on IHL which ran in early 2015, the students were divided into groups to each review one of these video scenarios. In the following class, each group then had to explain the legal issues raised by the combat situation covered in the video. In this first use of computer simulations in class, the law teachers had no input into the content of the scenarios, and the students were not able to control any aspect of the video as it ran (beyond pausing it to highlight specific points). At the end of the exercise, the students were surveyed anonymously for their feedback. Overall, there was a very positive response from the students. Out of a ranking of $0-10,92 \%$ of the class rated the use of computer simulations as 8 or above, with $50 \%$ rating them as 10 . As one student noted: the video simulations 'helped visualise a war scenario, therefore helping with knowledge on laws of war. ${ }^{51}$ The two key issues identified by the students were: i) the quality of the graphics (as one student noted: 'Improv[e] the graphics, if at all possible. That would improve the experience.'); and ii) increased interaction (one student highlighted that: 'the use of layered and complex simulations would illustrate the limitations of IHL better.') These student comments reflect the academic literature which has found that giving students a choice makes for a 'richer' gaming experience and that confronting students with the 'grim realities of combat ... make[s] training more realistic and useful., ${ }^{, 52}$

Based on the positive feedback from this first pilot use of computer simulations for teaching IHL, the Dean of the School of Law approved the use of interactive computer simulations with both undergraduate and postgraduate students. Funding was obtained from the

\footnotetext{
${ }^{51}$ All references come from class feedback obtained on 19 February 2015, copies on file with authors.

52 Brown et al n.39, p56.
} 
QUB e-AFFECT project to finance the purchase of the license to utilise the game Arma 3 (i.e. software) and a computer with sufficient processing power to run the game smoothly (i.e. hardware). The funding also allowed us to recruit a postgraduate IT expert to assist in the programming of the scenarios. While the initial pilot use with LLM students had been positive, the authors agreed that a series of benchmarks were required for the development of the interactive simulations. Following internal discussions, five key aspects were identified:

i. $\quad$ Realistic scenarios - without using real (and potentially graphic) images;

ii. Simple interface - so non-gamers were not disadvantaged by the assessment format;

iii. Ability to have branching scenarios - so the decisions students made in the simulation determined the questions they would have to answer;

iv. Timed assessment - so students needed to utilise real-time decision-making skills in addition to their knowledge of the law; and

v. Viewing the battlefield from different perspectives - so scenarios would be developed from perspective of: a Government legal advisor; rebel military commander; humanitarian worker; special forces behind enemy lines; and a General investigating alleged war crimes.

\section{ii. Scenario development and testing}

We created scenarios using the Arma 3 mission editor which gives a sandbox control to manipulate the game environment, artificial intelligence (AI) characters, and objects to design scenarios on a blank canvas. Such sandbox control in-game enabled us to provide bespoke learning opportunities and skill based development for students reflecting tensions in the real world application of IHL. ${ }^{53}$ Scenarios were developed, tested and then screen-recorded so that

\footnotetext{
53 C. Newbery-Jones, 'Ethical Experiments with the D-pad: Exploring the Potential of Video Games as a
} Phenomenological Tool for Experiential Legal Education' (2016) 50(1) The Law Teacher 61-81, p74. 
students would view the videos of the scenarios rather than have to know the controls and how to play the game. This was intended to level the playing field by removing any knowledge or experience in playing computer games as many students would not be familiar with the controls, and we were not assessing their gaming ability.

For consistency purposes, and to reduce the amount of information students would have to assimilate during the simulations, the authors decided that all the scenarios should take place within one conflict. Therefore, a realistic civil war context and narrative was developed based on the island of Altis. The narrative set out that the island had undergone a military coup in 1983 led by the National Liberation Party (NLP) which overthrew the democratically-elected government of the Altis Democratic Party (ADP). Between 1983 and 2013 the state was run as a one-party dictatorship by the NLP. However, in 2013 supporters of the former ADP President, with the support of the neighbouring state, undertook military operations to overthrow the military government. In the course of the fighting, there were large-scale defections of the NLP armed forces to the advancing ADP forces, resulting in the overthrow of the NLP dictatorship. However, small groups of loyal NLP soldiers fled to the east of the island resulting in the island being divided into areas under ADP control and areas under NLP control. A UN peacekeeping force was sent to monitor the two armed groups, and humanitarian agencies arrived to support the civilian population. This context would help to give the conflict a more contemporary and realistic feel, as well as require students to engage with the different legal regimes under IHL for international and non-international armed conflicts.

Once the overall context of the conflict was in place, it was necessary to develop the individual scenarios which the students would be faced with. The first consideration revolved around the specific aspects of IHL which were to be examined. Based on the fundamental principles outlined earlier, and reflecting the original ICRC-developed scenarios, it was decided that five scenarios would be developed covering: i) the principle of distinction; ii) the principle of proportionality; iii) humanitarian access for the ICRC; iv) war crimes; and v) specific 
responsibilities of special forces. It was also decided that the five scenarios would encompass multiple viewpoints (e.g. legal advisor to government forces, rebel commander, humanitarian worker), so that students would be immersed in the "fog of war". The experience of "participating" in a virtual conflict from these different perspectives was intended to enable students to develop new real-time skills, through having responsibility for resolving challenging scenarios that would otherwise not be possible or safe within a classroom setting.

The first scenario involved aerial footage of a convoy of trucks on a rural road, seen from the perspective of a Government armed drone in mid-flight. In their role as a military legal advisor, the students were informed that intelligence sources had stated that a high-ranking rebel commander was in the convoy, but the footage did not allow them to see whether the convoy was of a military or civilian nature. The students were then asked how they should respond in these circumstances, bearing in mind the principle of distinction. In the second scenario, the students were a NLP commander planning an attack on a government-controlled military base, which was situated in close proximity to civilian homes and markets. Students were given a series of options as to how the NLP should attack the base, ranging from suicide bombings to mortar fire, to test their understanding of the principle of proportionality. The third scenario involved the issue of humanitarian access, with the students taking on the role of a humanitarian worker negotiating with soldiers at an armed checkpoint in order to gain access to civilians in need. Options included returning when the localised armed hostilities were over, attempting to drive round the road block, or using an alternative route. The next scenario tested the students' knowledge of war crimes through a series of shots depicting various factions attacking medical facilities, civilian buildings and hostages during the course of a battle in a built-up urban environment. The final scenario was modelled on the Bravo Two Zero debacle of 1991, with a civilian shepherd wandering dangerously close to a concealed special forces unit. The students were asked whether the soldiers should kill, capture or ignore the civilian, thereby testing their 
understanding of IHL in the translucent circumstances of special forces operations behind enemy lines.

The design of these scenarios led to one of the more surprising outcomes of the project. Essentially, in trying to make the simulations as clear as possible for the students, the true complexities of humanitarian law became apparent. For example, when designing the first scenario involving the armed drone, it was discovered that the slightest increase or decrease in altitude affected the viewer's ability to determine whether the convoy was of a military or civilian character, and so whether it should be attacked or not. This highlighted the need for students to utilise their logical and spatial awareness intelligences in conjunction with their knowledge of the law. Similarly, the ambush of the military base by the NLP underscored the practical problems associated with the principle of proportionality, with seemingly reasonable options such as mortar fire still resulting in large numbers of civilian casualties. This therefore engaged both the inter- and intra-personal intelligences of the students in understanding the consequences of their decisions.

These variables benefitted the project in two ways. First, they made the project highly reflexive, in the sense that pedagogical outcomes were experienced by the staff as well as the students. Second, the resulting simulations were more reflective of the real-world challenges encountered by military personnel and humanitarian organisations in actual conflict zones. Such insights were particularly important since the simulations were part of the module assessment. Therefore, before the simulations could be used for assessment purposes, they were tested with a group of postgraduate students who had differing levels of knowledge of IHL. Overall, the testers reported back positively, both in terms of their interest in the exercise and on the learning objectives being tested. Feedback from these testing sessions on the issues such as the written instructions, video quality, and multiple choice questions led to some revisions and modifications of the scenarios. 


\section{iii. Classroom preparation and assessment}

Over the course of teaching the 12-week module we used a series of discrete mini scenarios to familiarise students with both the visual look of the computer simulations and the narrative backstory of the fictional civil war which was taking place on the island of Altis. As discussed in more detail in the following section, as the law teachers gained experience of using the computer simulations in class, it has become clear that a greater level of initial preparation and familiarisation is required for the class to be comfortable with the system, particularly if the simulation is to be used as an assessment exercise. As Brown and Knight have noted: '[w]e tend to assess what we have always assessed in the way we have always assessed it. ${ }^{94}$ Therefore, the original project proposed that the simulations would be used as part of the formal assessment for the undergraduate and postgraduate IHL modules. In recognition of the novel assessment format, it was agreed that the computer simulation would represent $20 \%$ of the module grade, while a more traditional written essay would comprise the remaining $80 \%$. While the simulation was only intended as a minor part of the module assessment, it introduced a more nuanced and practical element to the skills examined.

Boud argues that assessments in higher level education are meant to indicate to students what they should be learning and how they should go about it. ${ }^{55}$ Therefore, in order to design and deliver 'good' assessments, rather than simply the regurgitation of knowledge, learning assessments should be thought of in 'relational' terms, in the sense that 'learning is a function of both teaching and the context in which it occurs. ${ }^{56}$ Based on this approach, we intended that the use of computer simulations as an assessment exercise would assist in both student learning and in testing students' practical application of the law (which would be supplemented by their knowledge and critical analysis of the law through the written essay assignment). Such an approach was premised on Howard Gardner's insights that people possess eight or more

\footnotetext{
${ }^{54}$ S. Brown and P. Knight, Assessing Learners in Higher Education (London: Kogan Page, 1994) p101.

${ }^{55}$ D. Boud, 'Assessment and Learning: Contradictory or Complementary?' in P. Knight (ed), Assessment for Learning in Higher Education (Kogan Page: 1995) 35-48.

${ }^{56}$ Ibid.
} 
relatively autonomous intelligences. ${ }^{57}$ Gardner's theory of multiple intelligences posits that all people exhibit distinctive profiles of strengths and weaknesses, covering for example musical, linguistic and bodily-kinaesthetic intelligence. ${ }^{58}$ It is probable that many law students have a particular aptitude in linguistic intelligence and therefore would gravitate towards written forms of learning and assessment if given a choice. Indeed, Gardner himself has disparagingly referred to traditional IQ or US SAT score tests as only assessing 'the mind of the future law professor.' ${ }^{59}$ Computer simulations meanwhile draw on a range of students' intelligences, including their spatial awareness and logical-mathematical skills. Therefore, while simply assigning journal readings or assessing knowledge through written exercises may be less time consuming for lecturers, such an approach does not necessarily help to develop students' judgment or long-term skills applicable to their professional careers. ${ }^{60}$ Likewise, Newbery-Jones strongly criticises the continued outdated use of legal teaching methods and lack of new technologies in legal education, as a tutor based problem, not a student one, which is inhibiting the latter's employability. ${ }^{61}$

In order to prompt students to problematize their understanding and application of IHL, we decided that the best way to teach and assess using Arma 3 would be for students to be presented with a range of scenarios, and to provide them with a list of options to deal with the specific situation. Students would need to choose the correct course of action based on their knowledge and understanding of IHL. They were then confronted in the next screen with the consequences of their action. For example, in the first scenario utilising the armed drone, if they choose to fire on the convoy (instead of descending to verify that it was indeed a military target)

\footnotetext{
${ }^{57}$ See for example: K. Davies, J. Christodoulou, S. Seider \& H. Gardner, 'The Theory of Multiple Intelligences' in R. Sternberg and S. Kaufman (eds.), Cambridge Handbook of Intelligence (Cambridge University Press: 2011) 485-503.

${ }^{58}$ For the initial iteration of Gardner's theory, see: H. Gardner and T. Hatch, 'Multiple Intelligences Go to School: Educational Implications of the Theory of Multiple Intelligences' (1989) 18(8) Educational Researcher 4-10.

${ }^{59}$ H. Gardner, Multiple Intelligences: New Horizons in Theory and Practice (Basic Books: reprinted 2006) p.7.

${ }^{60}$ Boud, n.59; and G. Gibbs, Using assessment strategically to change the way students learn, in S. Brown and A. Glasner, Assessment Matters in Higher Education: Choosing and Using Diverse Approaches, Society for Research into Higher Education/Open University Press (1999), 41-53.

${ }^{61}$ Newbery-Jones, n.53, p68-69.
} 
they would see a video sequence showing that it was actually a humanitarian convoy and their attack had killed a number of civilians. Since the aim of the exercise was to test the students' knowledge of IHL, not their ability to play video games, the students did not control the characters or equipment (such as the drone) and the scene changes were predicated on their choices from a list of possible actions. Follow-up multiple choice questions assessed the students' knowledge and understanding in more depth, and provided an opportunity for students who chose the wrong course of action not to be overly penalised.

The computer simulations were first used during the academic year 2015-16 with an undergraduate class of around 40 students. Based on the feedback and experience, certain changes, as detailed in the next section, have been made. They have subsequently been used as a learning experience (but not a module assessment tool), as part of a voluntary simulated moot/role playing IHL competition for teams of undergraduate and postgraduate students. This approach was adopted due to the technical challenges of running the assessment and places more of an emphasis on team working and problem solving in a group, which more closely recreates real world discussions on the use of force by combatants and humanitarian actors.

\section{Challenges and Lessons Learnt}

\section{i. $\quad$ Technical and design issues}

There were a number of technical and practical challenges in developing the specific scenarios and the assessment system itself. First of all, designing and developing the scenarios, capturing the correct videos and building the console was very time intensive. By way of example, almost every single element of each scenario had to be generated individually within the game, including military installations, vehicles, troops with distinctive uniforms and fatigues, and even background elements such as weather conditions and lighting. Moreover, groups of combatants, vehicles and aircraft had to be given separate instructions, often governing their exact 
movements and modes of operation. Even with Arma 3's user-friendly mission editor, there was a steep learning curve that involved basic coding of scripts to follow cameras that would adequately capture the scenes needed for the assessment. This sometimes led to characters within the game not acting in a way that was appropriate for the planned scenario, reflecting our lack of knowledge of scripting these complex interactions. For the most part the artificial intelligence (AI) aspects of the game acted in a very responsive and complex manner, identifying targets, moving to objectives and trying to minimise injury to civilians without our intervention.

In terms of video editing we had to capture the correct scenes and angles to reflect the planned narrative of each scenario and good examples of the issues we were trying to capture. Very often this involved setting up each of the elements discussed above, recording the action from one angle, and then setting up the scene over and over again until all of the angles had been covered. For example, in the war crimes scenario where we intended to show a mass shooting of civilians, the AI soldiers immediately turned and shot the 'perpetrator' as a result of Arma 3's inclusion of certain laws of armed conflict within the game. Clever editing was therefore required for the war crime to appear as a pre-meditated group act. However, as a result, once these videos had been cut and converted they lost some of their visual quality.

\section{ii. Use of simulations as an assessment exercise}

While the plan had always been to use the computer simulations as part of the assessment for the IHL modules, a variety of issues arose when they were first used. Despite the prior testing, we had not replicated the larger-scale setting of a class of 40 undertaking the test at the same time. As a result our servers were unable to cope and the video replay during the assessment was uneven and slow, as too many students were accessing the same videos at the same time. This issue was compounded as we had set a 40-minute countdown timer to the assessment. This had been included so that the assessment would more accurately reflect the need to make immediate 
choices and thereby test real-time decision-making skills. However, this feature was built into the programme, and so we were unable to increase the time limit during the assessment to compensate for the slow video replay. This meant that some students did not finish or rushed the final questions leading to a negative impact on their overall scores.

Another issue which arose was that while some mini simulations had been demonstrated in class, the students were not confident with using the assessment method. This may reflect a certain conservatism in assessment methods that (law) students are comfortable with, particularly for final year students who are very conscious that a lower mark for one module may impact their overall degree. However, it also highlighted the need for more extensive examples to be provided in advance and opportunities for the students to undertake similar types of scenarios as they would be tested on. Reflecting the time intensive nature of developing the scenarios, the mini simulations used in class did not provide a sufficient guide to the students on how they would be assessed in the actual simulations. As Newble and Cannon have noted, for students their primary motivation is to pass the examination with a good mark and so knowing what to expect and what to revise can allay some of their concerns. ${ }^{62}$ It follows that new assessment methods through technology should perhaps be utilised as a formative tool in the first year, before progressing to a commensurate amount of the final module mark in subsequent years to help normalise expectations and to allow students to reflect on past assessment in previous years.

As a result of the technical issues in video playback, and the novelty of the assessment method, it was decided that the first undergraduate class that utilised the simulations were potentially unduly impacted, so their marks were ultimately not counted towards their final grade. Considering that this was a new assessment format, and that we were developing a complex series of scenarios which posed both technical and pedagogical challenges, with

\footnotetext{
62 D. Newble and R. Cannon, A Handbook for Teachers in Universities and College: A Guide to Improving Teaching Methods (Kogan Page: 1995) p94.
} 
hindsight we should have first utilised the simulations as a formative assessment, rather than a summative one. This would have allowed us to iron out the technical issues, but more importantly it would have led to a stronger learning experience for the students. It was noticeable in the assessment results that some of the decision-making by the students seemed particularly poor. For example, several students opted to use suicide bombers or to execute the unarmed civilian shepherd. These options had been included in the simulation as the 'obviously wrong' multiple choice options (from our perspective) under the expectation that no one in the class would actually choose them. This raises questions as to the level of understanding of the principles of IHL by those students, but also highlights the need for some form of written element to the simulations so that students can justify why they have chosen one type of action over another. In the less pressurised context of a formative, rather than assessed, exercise, subsequent classes can examine in detail the justifications given by students as to why they have chosen a particular course of action which in itself would prompt class discussion as to the applicable laws. Drawing on these initial outcomes, we have tried to simplify the use of Arma3 in class by moving to scripted scenarios were students can point and click with a mouse. We have also changed the format to group-based exercises to promote team work, as would occur in a conflict environment, whereby all team members give practical and legal advice on what decisions to make and actions to take, such as selection of military targets for a drone attack. While this represents a move away from integration of computer based problem solving in the assessment, it reflects a more measured use of Arma3 in class to develop problem solving skills that can be subsequently assessed through written problem questions.

\section{Conclusion}

Reflecting on this initiative to apply Gardner's theory of multiple intelligences and entry points to learning into the classroom, it is clear that pushing the boundaries of traditional approaches to teaching law can have its benefits and shortcomings. While a lot of time and effort was invested 
in the first year of the project, since the scenarios are now established they have been used in subsequent formative exercises. In the coming years, the quality and quantity of the available scenarios can be developed and refined through capturing additional game footage. Likewise, removing the scenarios as a summative assessment has allowed greater interaction for the students, with them controlling and deciding on the use of the weapons and tactics when playing the game in specially scripted missions and then discussing it with the rest of the class. The experience of developing this IHL project has reinforced our view that innovation takes time, but that such advances are necessary to complement the increasing use of technology in contemporary society. ${ }^{63}$ Although the original group of students may have felt that the assessment did not accurately reflect their knowledge, their feedback of the exercise was generally positive and they appreciated our attempt to vary the teaching delivery and assessment methods. This was reflected in very positive teaching evaluations and even more students signing up for the class in the academic year 2016-17. However, within the context of a university setting, it is clear that using computer games to teach international humanitarian law can be a beneficial way of accessing students' multiple intelligences and providing additional learning entry points to bridge the gap between black letter law and real world application.

\footnotetext{
${ }^{63}$ T. Gazzini, 'A Fresh Look at Teaching International Law - A Few Pedagogical Considerations in the Age of
} Communications’ Leiden Journal of International Law 29(4) (2016) 971-978. 